\title{
FIT FOR DUTY: THE HEALTH STATUS OF NEW SOUTH WALES PARAMEDICS
}

Alex James MacQuarrie BSc MBA $\operatorname{PhD}(c)^{1^{*}}$, Caroline Robertson BSc MSc $\mathrm{PhD}^{2}$, Peter Micalos BPE MEd PhD ${ }^{1}$, James Crane $\mathrm{BSc} \mathrm{PhD}^{3}$, Richard High $\mathrm{BPE}^{4}$, Eric Drinkwater BPE MPE PhD ${ }^{5}$, James Wickham BSc PhD $^{1}$

*amacquarrie@csu.edu.au

\section{OPEN ACCESS ARTICLE}

Recommended Citation: MacQuarrie AJ, Robertson C, Micalos P, Crane J, High R, Drinkwater $\mathrm{E}$, Wickham J. Fit for duty: the health status of New South Wales paramedics. Irish Journal of Paramedicine. 3(2). Dec 2018. https:// doi.org/10.32378/ijp.v3i2.109

Received: 25 Sep 2018

Revised: 03 Nov 2018

Accepted: 14 Nov 2018

Published: 11 Dec 2018

Copyright: (c) 2018, the authors. This is an Open Access article distributed under the terms of the Creative Commons Attribution-Non-CommercialShare Alike 4.0 International licence which permits use, distribution, and reproduction in any medium, provided the original work and any attributes thereof are properly cited, are distributed under the same licence, and that the work is not used for commercial purposes.

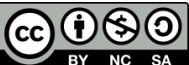

Funding/support: None declared.

Competing interests: None declared.

Provenance and review: Not commissioned, peer-reviewed.

\section{Author affiliations}

1. Charles Sturt University, NSW, Australia.

2. Three Rivers University Department of Rural

Health, NSW, Australia

3. University of Tasmania, Hobart, Tasmania,

Australia.

4. New South Wales Ambulance, NSW, Australia.

5. Deakin University, VIC, Australia.

\section{Abstract}

\section{Introduction}

Paramedics are health care workers who respond to medical emergencies. Paramedics exhibit high rates of injury and illness with markers of poor health. The aims of this study were to explore the self-reported health status of paramedics in New South Wales, Australia, and to compare it with that of the Australian general population and to examine paramedics' attitudes towards exercise.

\section{Methods}

In 2015, paramedics employed by NSW Ambulance were invited to complete a web-based survey composed of the Medical Outcomes Survey Short Form 36 (SF-36), measures of attitudes towards exercise and demographic information. Normative comparator data for the Australian general population (BMI and SF-36 scores) were sourced from the Household Income Labour Dynamics in Australia 2015 survey.

\section{Results}

Of the approximately 3,300 paramedics invited to participate, 747 completed the survey (507 male, 240 female). Mean age and mean years of service were 41.5 \pm 9.5 (SD) and $13.6 \pm 9.0$ respectively. Male paramedics scored higher than females $(p<0.001)$ in the Vitality domain of the SF-36, and regional paramedics had a higher General Health domain score than metropolitan paramedics $(p<0.05)$. Regional male paramedics had higher BMls than their metropolitan counterparts $(28.04 \mathrm{~kg} / \mathrm{m} 2 \pm 3.99$ vs. $26.81 \mathrm{~kg} / \mathrm{m} 2 \pm 4.67, \mathrm{p}=0.001)$. Compared to the Australian population, paramedics scored higher in the Physical Function domain $(p<0.001)$ but lower in summary scores for mental and physical health $(p<0.001)$. Paramedics' BMls were slightly higher than the general population $(27.10 \pm 4.30 \mathrm{~kg} / \mathrm{m} 2$ vs. $26.47 \pm 5.42, p<0.001)$. Paramedics reported lack of time, family commitments, and lack of motivation and in regional postings: distance to fitness facilities and shift patterns as barriers to exercise.

\section{Conclusions}

Paramedics scored lower on the SF-36 than the general population, which can indicate a lower health-related quality of life. High BMI and low SF-36 scores may be related to a perceived inability to engage in regular exercise. Increasing BMI can be associated with the development of markers of poor health. Attention is needed to ensure that paramedics are "fit for duty". Ambulance management should foster innovative health promotion programs and paramedics need to recognise and value good health.

Keywords: illness; fitness; wellness; injury; ambulance; exercise 


\title{
Introduction
}

Paramedicine is recognized as a physically demanding profession. Examples of demanding manual tasks that paramedics routinely perform range from lifting and carrying patients (1-3), loading and unloading stretchers (4), to performing cardiopulmonary resuscitation (5-7) for extended periods of time. This is coupled with the requirement to undertake clinical decision-making in complex, often uncontrolled social environments on a rotating shiftwork schedule. $(8,9)$ Yet working paramedics have reported poorer health-related quality of life (HRQoL) and are more likely to be overweight or obese, as estimated by BMI (10-12), than comparator populations.(13) HRQoL is a valuable predictor of other indicators of health status, such as number of physician visits and hospitalisations, and mortality among adults(14) Specifically, rates of hypertension (15), obesity (16) and musculoskeletal injury (17-20) are higher in emergency responders (fire, police and paramedics) than other occupations. In addition, another contributing factor for working paramedics could potentially be linked to where they live and work. For instance, people living in rural and remote areas, where access to goods and services can be restricted, have been reported to experience poorer health than urban dwellers.(21) Approximately 50\% of paramedics employed by NSW Ambulance are reported to work in regional areas (as defined by NSW Ambulance) therefore potentially resulting in compromised health due to a lack of access to services and activities.

Over the long term, fatigue, lack of fitness, location and high rates of injury may contribute to poorer health outcomes in paramedics. $(8,22-25)$. This may be compounded by the likelihood of a higher BMI and therefore, an increased risk for metabolic diseases such as Type II diabetes and cardiovascular disease and with earlier mortality. $(26,27)$ Despite the well-known benefits of regular physical activity for optimum physical and mental health (28-31) the potential benefits of these for paramedics has not been widely examined. As well, there is a paucity of research on health status and gender in ambulance services.

\begin{abstract}
Aim
The primary aim of this study was to explore the self-reported health status of paramedics employed by a large ambulance service in New South Wales, Australia (NSW Ambulance) by gender and geographic rostering pattern (metropolitan and regional) and to compare these results with that of the Australian general population. A secondary aim was to examine paramedics' attitudes towards exercise and to determine whether paramedics thought that they exercised enough including barriers (if any) that may prevent them from exercising enough.
\end{abstract}

\section{Methods}

Study design and procedures

A web-based survey was conducted using a cross-sectional methodology. An email containing a link to the survey instrument was sent to paramedics' corporate email accounts. The survey was open for 30 days from 11 May 2015 and a reminder email was sent on day 15. Potential participants were informed that no explicitly identifying information would be collected. The survey took approximately 10 minutes to complete.

\section{Participants}

All paramedics and trainee paramedics employed by NSW Ambulance as of May 2015 $(\mathrm{n}=3,302)$ were invited to participate in the study regardless of age, gender, years of service, training pathway, level of certification (trainee; intern; qualified; intensive care; extended care; or specialist group: such as, special operations and special casualty access), primary role or geographic rostering (metropolitan or regional). Completing the survey signified consent to participate in the research. Once the survey was completed, there was no opportunity for participants to withdraw their data. Ethical approval was obtained from the South Eastern Sydney Local Health District Human Research Ethics Committee (HREC Reference number: 15/031, LNR/15/POWH/68) and Charles Sturt University Human Research Ethics Committee (HREC Protocol number 2015/011). 


\section{Instrumentation}

The survey consisted of three parts: Demographic information (age, gender, height, weight, level of certification, rostering, primary role), the Medical Outcomes Survey Short Form 36 (SF-36) (32), widely used in monitoring population health and reporting health related quality of life (HRQoL) $(26,27)$ and questions examining attitudes towards exercise.

\section{Medical Outcomes Survey Short Form 36}

The SF-36 consists of 36 questions that, when scored, measure eight health domains: Physical Functioning (PF); Role Limitations due to Physical Health Problems (RLP); Role Limitations due to Personal or Emotional Problems (RLEP); Bodily Pain (BP); Vitality (V), Social Functioning (SF); Mental Health (MH); and General Health Perceptions $(\mathrm{GH})$. The possible scores for each domain range from zero to 100, with 100 representing the best possible health state. These scores contribute to the construction of two summary measures: Physical Health Summary (PHS) and Mental Health Summary (MHS).(33) Each of these has possible scores from zero to 100, with 100 representing the best possible health state.

\section{Attitudes towards exercise}

Two questions examined attitudes towards exercise:

1. Are you currently exercising as much as you would like?

2. "What are the barriers to you not exercising as much as you would like?"

This question could be answered in free text or the paramedics could choose one or more of the following items:

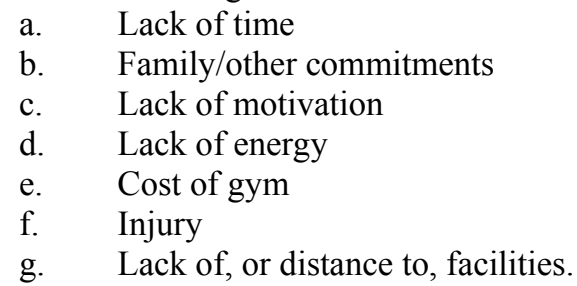

Comparative normative data

SF-36 data for the Australian population has been collected in national health surveys $(34,35)$ including most recently in the Household, Income and Labor Dynamics in Australia (HILDA) survey.(36) Age matched HILDA data for 2015 ( $\mathrm{n}=12,373$ ) was used as Australian population normative data to compare SF-36 results and BMI ( $\mathrm{n}=$ 8,600).(37) The age range for the Australian data was set at 20-70 years old as this reflects the youngest to the oldest currently employed NSW Ambulance paramedic.(R. High, personal communication, October 15, 2015).

\section{Data analysis}

Body Mass Index (BMI) was calculated for both NSW Ambulance respondents and HILDA comparator data using the formula BMI = body weight $(\mathrm{kg}) /$ height $\left(\mathrm{m}^{2}\right)$. The eight SF-36 domains and the PHS and MHS were scored in accordance with Ware.(38) The question on barriers to exercise yielded qualitative responses that were themed into categories by the primary author.

Prior to statistical analysis data were inspected visually and statistically for normality and are presented as mean \pm standard deviation. A Pearson Chi-square test of independence was performed to establish the representativeness of the survey respondents compared to the NSW Ambulance population based on gender and posting. Differences between paramedics' SF-36 responses and the Australian population, and the responses of male vs female paramedics and regional vs metropolitan paramedics were calculated and descriptive statistics and one way ANOVA employed where the requirements for parametric tests were met. A Pearson Population Correlation Hypothesis Test was computed to assess the relationship between SF-36 scores and BMI. All analyses were performed using SPSS Version 17.0 (Statistical Package for the Social Sciences Version 17.0, SPSS Inc., Chicago, Illinois, U.S.A.) with the threshold for statistical significance set at $\mathrm{p}<0.05$. XLStat (Addinsoft SARL, New York, NY, USA) 
was used to impute missing data in the NSW Ambulance SF-36 results using the NIPALS method (39) to allow principal component analysis with missing values. The NIPALS algorithm was applied to the NSW Ambulance dataset and the obtained PCA model is used to predict the missing values.(40) Of the total number of items on the SF36 survey $(26,982)$ a total of $538(1.9 \%)$ were not answered and therefore imputed.

\section{Results}

Response rate and demographics

Of 3,302 paramedics employed by NSW Ambulance in May 2015, 22\% (747 total, 507 males) completed the survey yielding an overall response rate of $22 \%$ (Table 1).

\begin{tabular}{|r|c|c|c|}
\hline & Regional & Metropolitan & All \\
\hline Males & $\mathrm{n}=268$ & $\mathrm{n}=239$ & $\mathrm{n}=507$ \\
\hline Age (years) & $44.27(9.48)$ & $42.66(9.3)$ & $43.51(9.42)$ \\
\hline Years of Service & $15.37(9.7)$ & $14.45(9.09)$ & $14.93(9.98)$ \\
\hline Females & $\mathrm{n}=111$ & $\mathrm{n}=129$ & $\mathrm{n}=240$ \\
\hline Age (years) & $36.97(8.18)$ & $37.39(8.49)$ & $37.20(8.33)$ \\
\hline Years of Service & $10.36(6.56)$ & $9.53(5.55)$ & $9.98(6.12)$ \\
\hline
\end{tabular}

Table 1. Demographic information NSW Ambulance Paramedics (mean \pm SD)

The results of the Pearson Chi-square test of Independence showed the overall proportion of survey respondents were not significantly different than the NSW Ambulance population by gender $\left(\chi^{2} 3.6554\right.$, df $1, \mathrm{p}=0.05589$, CI $\left.-0.0490,0.0002\right)$ but were significantly different by posting $\left(\chi^{2} 10.06, \mathrm{df} 1, \mathrm{p}=0.001515\right.$, CI $\left.0.8331,0.0629\right)$.

Sixty-three per cent of respondents were qualified paramedics $(n=471) ; 21 \%$ were intensive care paramedics $(n=154) ; 7 \%$ were specialist group (e.g. special operations team, special casualty access team $)(n=53) ; 6 \%$ were intern paramedics $(n=$ 41); $2 \%$ were extended care paramedics $(n=17)$; and $2 \%$ were trainee paramedics $(n=$ 11). Participants' primary roles included: clinically practicing $(89 \%) \quad(n=667)$, management $(6 \%)(n=45)$, education $(2.9 \%)(n=22)$ control centre $(1.5 \%)(n=11)$, other, i.e., information technology $(0.01 \%)(n<5)$.

\section{SF-36: NSW Ambulance paramedics}

There were no significant differences by gender except for the Vitality domain where males scored higher $(57.61 \pm 16.29$ versus $53.17 \pm 18.37, \mathrm{p}=0.001$, CI 1.716, 7.7178). By posting there were no significant differences except for General Health domain where regional paramedics scored higher than metropolitan paramedics $(66.50 \pm 18.95$ versus $63.85 \pm 17.89, \mathrm{p}=0.05)$.

\section{SF-36: NSW Ambulance vs Australian population}

There were significant differences in 6 of the 8 domains $(\mathrm{p}<0.001)$ as well as in the Physical Health Summary score $(\mathrm{p}<0.001$ CI 1.680, 3.958) and Mental Health Summary score ( $\mathrm{p}<0.001$, CI 6.994, 9.363), with paramedics reporting lower scores (more disability) in both domains than the Australian population. In the Physical Function domain, paramedics scored significantly higher (less disability) $(\mathrm{p}<0.001$ CI -4.323 , 2.952) than the Australian population (Table 2).

Body Mass Index (BMI): NSW Ambulance paramedics

There were differences in overall mean BMI scores by gender: male's BMI $(\mathrm{n}=507)$ $27.53 \pm 4.05 \mathrm{~kg} / \mathrm{m}^{2}$ was higher than female's BMI $(\mathrm{n}=240) 26.61 \pm 4.38 \mathrm{~kg} / \mathrm{m}^{2}(\mathrm{p}=0.001$ CI $0.499,2.059)$. By posting, there were differences between regional paramedics $(\mathrm{n}=$ $379)$ with higher BMI than metropolitan paramedics $(n=368)\left(27.49 \pm 4.30 \mathrm{~kg} / \mathrm{m}^{2}\right.$ vs $26.60 \pm 5.12 \mathrm{~kg} / \mathrm{m}^{2}, \mathrm{p}=0.01$, CI $\left.-1.57,-0.218\right)$. With regard to location and gender, regional males $(n=268)$ had higher BMI than metropolitan males $(n=239)(28 \pm 3.99 \mathrm{~kg} /$ $\mathrm{m}^{2}$ vs $26.8 \pm 4.67 \mathrm{~kg} / \mathrm{m}^{2}, \mathrm{p}=0.001$, CI $\left.-1.99,-0.468\right)$ whilst there were no significant differences in mean BMI between regional $(n=129)$ and metropolitan $(n=111)$ females $\left(26.17 \pm 4.75 \mathrm{~kg} / \mathrm{m}^{2}\right.$ vs $\left.26.19 \pm 5.85 \mathrm{~kg} / \mathrm{m}^{2}, \mathrm{p}=0.977, \mathrm{CI}-1.343,1.383\right)$. 
NSW Ambulance and Australian population

There was a difference between the Australian population's mean BMI score $(26.47 \pm$ $\left.5.42 \mathrm{~kg} / \mathrm{m}^{2}\right)$ and paramedics' $\left(27.10 \pm 4.30 \mathrm{~kg} / \mathrm{m}^{2}\right)(\mathrm{p}<0.01$, CI $-0.850,-0.126)$.

Exercise

Responses to the question: "Are you currently exercising as much as you would like?" found that $72 \%(n=548)$ of all respondents reported 'No'. Those answering 'No' had significantly higher BMI scores than those answering 'Yes' $\left(27.5 \pm 4.91 \mathrm{~kg} / \mathrm{m}^{2}\right.$ vs $25.9 \pm$ $\left.4.02 \mathrm{~kg} / \mathrm{m}^{2}, \mathrm{p}=0.001, \mathrm{CI}-2.29,-0.90\right)$.

\begin{tabular}{|c|c|c|c|}
\hline & $\begin{array}{c}\text { NSWA Survey } \\
(n=747) \\
\text { Mean (SD) }\end{array}$ & $\begin{array}{c}\text { Australian Population } \\
(n=12,393) \\
\text { Mean (SD) }\end{array}$ & $\begin{array}{c}\text { Significance level } \\
(1 \text { tailed) }\end{array}$ \\
\hline Physical Function & $91.58(8.27)$ & $88.09(19.04)$ & $<.001$ \\
\hline Role Physical & $\mathbf{8 0 . 5 8 ( 3 0 . 0 6 )}$ & $\mathbf{8 6 . 6 7 ( 2 9 . 9 8 )}$ & $<.001^{*}$ \\
\hline Body Pain & $75.82(18.88)$ & $76.40(21.0)$ & $>.05$ \\
\hline General Health & $\mathbf{6 5 . 2 1 ( 1 8 . 4 0 )}$ & $\mathbf{7 0 . 3 7 ( 1 8 . 9 1 )}$ & $<.001^{*}$ \\
\hline Vitality & $\mathbf{5 6 . 2 0 ( 1 7 . 0 4 )}$ & $\mathbf{6 1 . 6 9 ( 1 8 . 2 6 )}$ & $<.001^{*}$ \\
\hline Social Function & $\mathbf{7 0 . 1 8 ( 1 7 . 7 0 )}$ & $\mathbf{8 6 . 2 2 ( 1 9 . 4 3 )}$ & $<.00$ * $^{*}$ \\
\hline Role Emotional & $\mathbf{7 4 . 0 8 ( 3 7 . 3 1 )}$ & $\mathbf{8 7 . 6 2 ( 2 7 . 9 3 )}$ & $<.001^{*}$ \\
\hline Mental Health & $74.54(16.40)$ & $75.24(16.0)$ & $>.05$ \\
\hline Physical Health Summary & $\mathbf{7 3 . 5 5 ( 1 4 . 5 4 )}$ & $\mathbf{7 6 . 6 5 ( 1 4 . 9 6 )}$ & $<.001$ \\
\hline Mental Health Summary & $\mathbf{6 8 . 0 2 ( 1 6 . 0 8 )}$ & $\mathbf{7 6 . 2 3 ( 1 5 . 0 6 )}$ & $<.001$ * \\
\hline
\end{tabular}

Table 2. SF36 Scores NSW Ambulance and Australian Population. Note an $\left({ }^{*}\right)$ denotes a clinically meaningful difference according to Ware (1994).

Barriers to Exercise

Lack of Time was the most frequently selected barrier followed by Family/Other, Lack of Motivation and Cost of Gym. Barriers to exercise were not different by posting except for Lack of, or Distance to Facilities (Figure 1 overleaf).

Free text responses describing barriers to not exercising as much as you would like ( $n=117)$ were examined and themed into six categories: $(1)$ on call $(n=62,53 \%),(2)$ roster $(n=19,16.2 \%),(3)$ other (e.g. injury) $(n=16,13.3 \%)$, (4) lack of energy/fatigue $(\mathrm{n}=9,7.7 \%)$, (5) study $(\mathrm{n}=7,6 \%)$, and (6) gym access $(\mathrm{n}=4,3.4 \%)$. 'On call' is a specific type of rostering where a paramedic may spend a portion of time not at station but responsible for responding to emergency calls before, during or after regularly scheduled shifts at station. On call rostering is predominantly utilised in regional postings.

\section{Discussion}

The primary aim of this study was to explore the self-reported health status of paramedics employed by New South Wales Ambulance, by gender and geographic rostering pattern (metropolitan and regional) and to compare those to the Australian general population. A secondary aim was to examine paramedics' attitudes towards exercise and to determine whether paramedics thought that they exercised enough, including barriers (if any) that may prevent them from exercising enough.

$S F-36$

In regard to SF-36 results by gender and posting, there were significant differences only in Vitality and General Health domains suggesting little difference in these paramedics report overall HRQoL. There is little in the literature to utilise as occupational comparators for paramedics, however recent research by Pek et al. (41) on the health of paramedics working in Hungary reported SF-36 scores similar in respect to NSW Ambulance paramedics. Both groups reported lower scores on the Vitality domain which 
Lack of Time

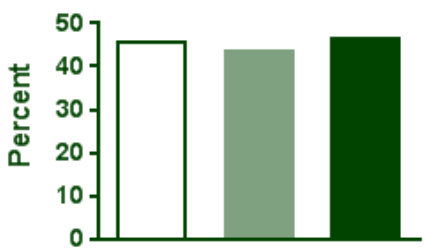

Lack of Energy

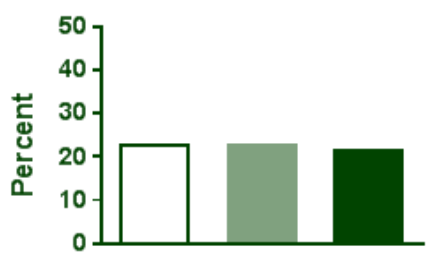

Lack of, or distance to Facilities

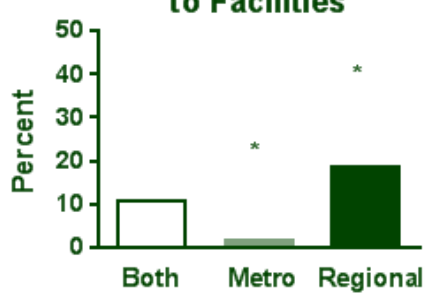

Family/Other Commitments

Lack of Motivation

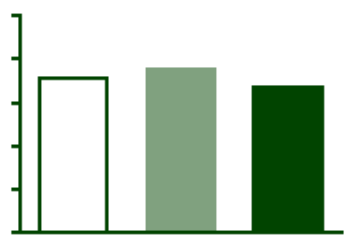

Cost of Gym

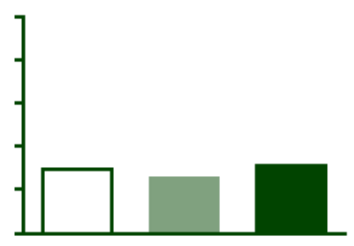

Childcare

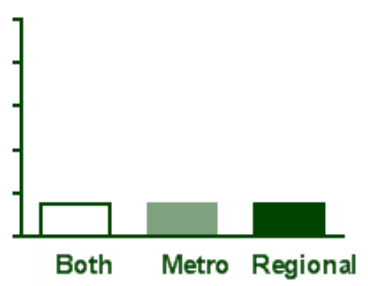

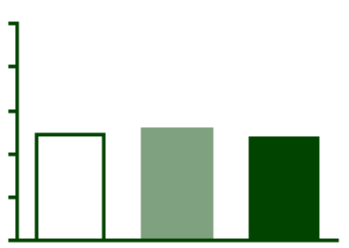

Injury

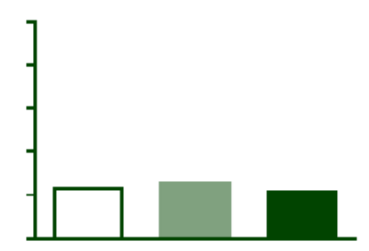

Lack of Knowledge

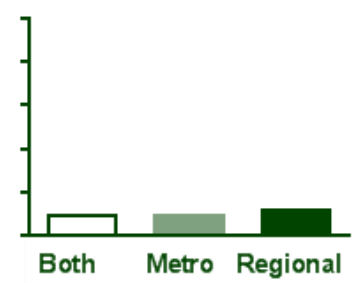

Figure 1. Barriers to Exercise by posting illustrates the frequency of paramedic responses to perceived barriers. Note the significant difference $\left({ }^{*} p<0.001\right)$ in response rate (regional versus metropolitan) for lack of or distance to facilities.

can indicate feeling tired and worn out. The lack of disparity in scores in gender and posting has been reported in one other study of paramedics using the SF-36 where they found no difference by emergency unit.(42) It could indicate that the work of a paramedic influences the respondent regardless of these variables.

The importance of monitoring the health status of paramedics is illustrated when examining their scores compared to the general population. Paramedics did score higher in Physical Function, but reported lower scores in six of the eight domains and both summary scores. There is a paucity of literature on the HRQoL in paramedics, so must be examined indirectly. The work by Courtney et al. (8) reported high levels of fatigue and poor health in paramedics in Victoria, Australia, due to shiftwork and occupational demands, which could contribute to the understanding of paramedics' lower SF-36 scores. The Victorian paramedics also reported lower levels of physical activity than the population and this was linked to shiftwork patterns.

\section{Body Mass Index}

Published literature suggests that a BMI of $18.5-24.9 \mathrm{~kg} / \mathrm{m}^{2}$ is a normal weight. Above that cutoff, there is an increased association with higher all-cause mortality.(26, 27) The average BMI of NSW Ambulance paramedics was $27.1 \pm 4.31 \mathrm{~kg} / \mathrm{m}^{2}$. These findings are consistent with a study of US paramedics $(\mathrm{n}=19,960)$ of $27.7 \pm 4.96 \mathrm{~kg} / \mathrm{m}^{2}(43)$ but were lower than a study of Canadian paramedics $(\mathrm{n}=295)$ of $29.8 \pm 4.9 \mathrm{~kg} / \mathrm{m}^{2}$. By gender and posting, regional rostered male paramedics had significantly higher BMI than their metropolitan counterparts. There appears to be no substantive literature about BMI in paramedics with regard to rostering or geographic area, therefore, it is hard to comment if this is a clinically significant finding in this paramedic service. Regional paramedics appear to follow the trend of rural Australians in having a higher BMI than their urban counterparts.(44) However, noting that call volumes are generally lower in regional compared to metropolitan areas in NSW Ambulance this could contribute to reduced 
physical activity during work hours as the paramedic awaits the next call. This would be consistent with a U.S. study that found urban nurses had higher levels of physical activity and lower BMIs than rural nurses.(45) Certainly, regular physical activity, even if jobrelated incidental, or more structured exercise can positively influence BMI.(46) Furthermore, this could contribute to the high rates of illness and injury as has been reported in other studies.(47) Prehypertension and hypertension have already been reported in up to $75 \%$ of emergency responders (15) and a Canadian study of paramedics reported similar rates of overweight and obesity ( $79 \%$ of respondents), the majority also reported at least one cardiovascular risk factor.(48) Given the relatively young workforce as reported in this study (mean age $41.5 \pm 9.5$ years old) an increasing BMI might contribute to diminished health outcomes as their careers progress.

Paramedics had a higher BMI than the Australian population although the mean for both populations falls in the BMI category of overweight. This difference is small $\left(0.6 \mathrm{~kg} / \mathrm{m}^{2}\right)$ so results should be interpreted with caution. Both populations could have a higher chance of early mortality (7\% higher compared to healthy BMI) as reported by to Di Angelantonio et al. (2015).(27) It must be noted that BMI defines height/weight characteristics. It is not a useful indicator of percent body fat.(12)

\section{Barriers to Exercise}

Paramedics overwhelmingly stated they are not exercising as much as they would like to. They also identified a series of barriers to not exercising as much as they would like. Both metropolitan and regional paramedics identified 'lack of time' and 'family or other commitments' as preventing adequate exercise. This could be expected given the nature of shift work and the age group of the participants, which would include many young parents. Interestingly, compared to metropolitan paramedics, regional paramedics were more likely to select 'lack of, or distance to facilities' as a barrier to exercise. This draws attention to the need for paramedics to have access to exercise facilities, for instance in the workplace. Many of the respondents (53\%) indicated that being 'on call' is a barrier to exercise, therefore, this type of rostering should be examined with regard to allowing time to exercise. The implication is that access to facilities and/or time to engage in regular physical activity could contribute to a healthier paramedic with more functional capacity for the physical demands of job performance.

In examining solutions for paramedics' low health status, Merrill (49) presented recommendations for health improvement. These included service-specific exercise education and functional movement training, and general physical ability assessment with lifestyle advice (e.g. healthy eating). Further, they advocate the use of peer fitness trainers as well as support by management. It has been reported that NSW Ambulance has introduced the 'Fitness Passport' program across all stations and this is seen as a positive move. This is a corporate health and fitness program that allows its members to access a wide range of their local health and fitness suppliers.(50) Uptake may be limited in regional areas based on the lower levels of participation of gyms and health clubs. A number of regional stations have recently taken part in a research project examining the effect of an on station physical fitness program.

\section{Limitations}

The use of corporate email to inform and solicit potential study paramedics may have limited participation (for example if the paramedic did not check his/her email account during the study period or if they were concerned about confidentiality). Similarly, the reminder email sent through to corporate email accounts may have limited participation for the same reason. NSW Ambulance survey data was collected using an online survey while the HILDA data was collected through telephone survey. It is worth noting that there may be a selection bias in this study as only those paramedics who wanted to complete the survey did so.

BMI is not accurate in estimating percent body fat and is used in the context of this study for its associations with other measures of health status. It is worth noting that self-reported height and weight is known to underestimate BMI though the magnitude of bias is small.(51) Use of the question regarding barriers to exercise may have been leading, however 117 paramedics validated the question by responding with their own open text responses. 


\section{Conclusion}

Health status based on SF-36 and BMI results differed among NSW Ambulance paramedics. Relatively uniform SF-36 scores within the population of paramedics suggest that, as an occupation, their HRQoL may be adversely affected by their job. In terms of BMI, regional-rostered paramedics had significantly higher BMIs than those posted to metropolitan areas and this may be due to shift pattern, lower call volume and therefore more sedentary time and a lack of suitable exercise facilities. The NSW Ambulance paramedics reported generally lower health status scores than the Australian population, which is noteworthy. This would indicate a need to measure and compare the two groups longitudinally. Both the paramedics and the Australian population have BMI's that are higher than that termed normal and could indicate an elevated risk for metabolic disease.

Paramedics have a responsibility to maintain their own health as they look after the health issues of their patients. Paramedic services have an opportunity to be an active partner with the paramedic to ensure that the workforce is as healthy and productive as possible. For both, there must be an attention to the potential risks to the health of paramedics in this very challenging and demanding occupation, and identifying strategies to mitigate those risks.

\section{References}

1. Lavender SA, Conrad KM, Reichelt PA, Johnson PW, Meyer F. Biomechanical analyses of paramedics simulating frequently performed strenuous work tasks. Appl Ergonomics. 2000;31(2):167-77.

2. Leyk D, Rohde U, Erley O, Gorges W, Essfeld D, Erren TC. Maximal manual stretcher carriage: performance and recovery of male and female ambulance workers. Ergonomics. 2007;50(5):752-62.

3. Barnekow-Bergkvist M, Aasa U, Ängquist KA, Johansson H. Prediction of development of fatigue during a simulated ambulance work task from physical performance tests. Ergonomics. 2004;47(11):1238-50.

4. Fischer S. Canadian Safety and Security Program - Physical Demands Analysis. Ottawa, Ontario: Center for Security Science; 2014.

5. Ashton A, McCluskey A, Gwinnutt CL, Keenan AM. Effect of rescuer fatigue on performance of continuous external chest compressions over 3 min. Resuscitation. 2002;55(2):151-5.

6. Havel C, Herkner H, Haugk M, Richling N, Riedmuller E, Trimmel H, et al. Physical strain on advanced life support providers in different out of hospital environments. Resuscitation. 2008;77(1):81-6.

7. Ko PC, Wang HC, Chiang WC, Yang CW, Ma MH. Comprehensive evaluation for quality of prehospital CPR. Resuscitation. 2008;78(1):98-9.

8. Courtney JA, Francis AJP, Paxton SJ. Caring for the Carers: Fatigue, Sleep, and Mental Health in Australian Paramedic Shiftworkers. Australian \& New Zealand Journal of Organisational Psychology. 2010;3(1):32-41.

9. Campeau AG. The space-control theory of paramedic scene-management. Symb Interact. 2008;31(3):285-302.

10. Huxley R, Mendis S, Zheleznyakov E, Reddy S, Chan J. Body mass index, waist circumference and waist:hip ratio as predictors of cardiovascular risk - a review of the literature. Eur J Clin Nutr. 2010;64:4.

11. Clark S, Rene A, Theurer WM, Marshall M. Association of Body Mass Index and Health Status in Firefighters. J Occup Environ Med. 2002;44(10).

12. Nuttall FQ. Body Mass Index: Obesity, BMI, and Health: A Critical Review. Nutrition Today. 2015;50(3).

13. Sterud T, Oivind E, Hem E. Health Status in the ambulance services: a systematic review. BMS Health Services Research. 2006;6(82):10.

14. Dominick KL, Ahern M, Gold C, Heller DA. Relationship of health-related quality of life to health care utilization and mortality among older adults. Aging Clinical Experimental Research. 2002;14(6).

15. Kales, Tsismenakis AJ, Zhang C, Soteriades ES. Blood Pressure in Firefighters, Police Officers, and Other Emergency Responders. Am J Hypertens. 2009;22 (1):11-20. 
16. Tsismenakis AJ, Christophi CA, Burress JW, Kinney AM, Min K, Kales SN. The Obesity Epidemic and Future Emergency Responders. Obesity 2009;17(8):164850 .

17. Maguire BJ, O'Meara P, Brightwell R, O'Neill B, Fitzgerald G. Occupational injury risk among Australian paramedics: an analysis of national data. Med $\mathrm{J}$ Aust. 2014;200(8):4.

18. Maguire BJ, Smith S. Injuries and Fatalities among Emergency Medical Technicians and Paramedics in the United States. Prehosp Disaster Med. 2013;FirstView:1-7.

19. Broniecki M, Esterman A, May E, Grantham H. Musculoskeletal disorder prevalence and risk factors in ambulance officers. J Back Musculoskeletal Rehab. 2010;23:165-74.

20. Betlehem J, Horvath A, Jeges S, Gondocs Z, Nemeth T, Kukla A, et al. How Healthy are Ambulance Personnel in Central Europe? Eval Health Prof. 2013;00 (0):13.

21. Dixon J, Welch N. Researching the Rural-Metropolitan Health Differential Using the 'Social Determinants of Health'. Aust J Rural Health. 2000;8(5):254-60.

22. Boreham CA, Gamble RP, Wallace W, Cran G, Stevens AB. The health status of an ambulance service. Occup Med. 1994;44(3):3.

23. Bennett P, Williams Y, Page N, Hood K, Woolard M. Levels of mental health problems among UK emergency ambulance workers. Emerg Med J. 2004;21:2356.

24. Gamble RP, Stevens AB, McBrien H, Black A, Cran GW, Boreham C. Physical fitness and occupational demands of the Belfast Ambulance Service. Br J Ind Med. 1991;49(9):4.

25. Buzga M, Jirak Z, Buzgova R. State of Physical Health and Fitness of Paramedics in the Czech Republic. Wulfenia Journal. 2015;22(3):8.

26. Berrington de Gonzalez A, Hartge P, Cerhan J, Flint A, Hannan L, MacInnis R, et al. Body-mass index and mortality among 1.46 million white adults. New Engl J Med. 2010;363(23):8.

27. Di Angelantonio E, Bhupathiraju S, Wormser D, Gao P, Kaptoge S, Berrington de Gonzalez A, et al. Body-mass index and all-cause mortality: individual-participant -data meta-analysis of 239 prospective studies in four continents. Lancet. 2016;388(10046):10.

28. Caspersen CJ, Powell KE, Christenson GM. Physical activity, exercise, and physical fitness: definitions and distinctions for health-related research. Public Health Rep. 1985;100(2):126-31.

29. Diepetro L. Physical Activity in Aging: Changes in Patterns and Their Relationship to Health and Function. J Gerontol A Biol Sci Med Sci. 2001;56A (Special Issue II):9.

30. Australian Government Department of Health. Australia's Physical Activity and Sedentary Behaviour Guidelines. In: Health Do, editor. Canberra, Australia: Australian Government; 2017. p. 8.

31. Lindsay D, Devine S, Sealey R, Leicht A. Time kinetics of physical activity, sitting and quality of life measures within a regional workplace: a cross-sectional analysis. BMC Public Health. 2016;16(786):9.

32. Gandek B, Sinclair S, Kosinski M, Ware J. Psychometric Evaluation of the SF-36 Health Survey in Medicare Managed Care. Health Care Financ Rev. 2004;25 (4):20.

33. Ware J, Kosinski M, Keller SD. SF-36 physical and mental health summary scales: a user's manual. Boston: The Health Institute; 1994.

34. Trewin D. 1995 National Health Survey SF36 Population Norms. In: Statistics ABo, editor. Canberra: Australian Bureau of Statistics; 1995. p. 40.

35. Trewin D. 2001 National Health Survey Summary of Results. Canberra: Australian Bureau of Statistics; 2001.

36. Wilkins R. Families, Incomes and Jobs, Volume 9. Melbourne: Melbourne Institute of Applied Economic and Social Research; 2014.

37. Butterworth P, Crosier T. The validity of the SF-36 in an Australian National Household Survey: demonstrating the applicability of the Household Income and 
Labour Dynamics in Australia (HILDA) Survey to examination of health inequalities. BMC Public Health. 2004;4(1):1-11.

38. Ware J, Snow K, Kosinski M, Gandek B. SF-36 health survey manual and interpretation guide. The Health Institute, Boston; 1993.

39. Wold H. Causal Flows with Latent Variables: Parting of the ways in the light of NIPALS modelling. European Economic Review. 1974;5(1):18.

40. Wasito I, Mirkin B. Nearest neighbours in least-squares data imputation algorithms with different missing patterns. Comput Stat Data Anal. 2006;50:23.

41. Pek E, Fuge K, Marton J, Banfai B, Csaszarne Gombos G, Betlehem J. Crosssectional survey on self reported health of ambulance personnel. Scandanavian Journal of Trauma, Resuscitation and Emergency Medicine. 2015;23(14):12.

42. Betlehem J, Gondocs Z, Jeges S. Major contributing factors of self percieved health in Hungarian ambulance personnel. Magyar Mentesugy. 2013;1(4):12.

43. Studnek JR, Bentley M, MacCrawford J, Fernandez AR. An Assessment of Key Health Indicators among Emergency Medical Services Professionals. Prehosp Emerg Care. 2010;14(1):14-20.

44. Simmons D, McKenzie A, Eaton S, Cox H, Khan MA, Shaw J, et al. Choice and availability of takeaway and restaurant food is not related to the prevalence of adult obesity in rural communities in Australia. Int J Obesity. 2005;29:7.

45. James P, Troped P, Hart J, Joshu C, Colditz G, Brownson R, et al. Urban Sprawl, Physical Activity, and Body Mass Index: Nurses' Health Study and Nurses' Health Study II. Am J Public Health. 2013;103(2):369-75.

46. Almajwal AM. Correlations of Physical Activity, Body Mass Index, Shift Duty, and Selected Eating Habits among Nurses in Riyadh, Saudi Arabia. Ecol Food Nutr. 2015;54(4):397-417.

47. Kuehl KS, Kisbu-Sakarya Y, Elliot DL, Moe EL, DeFrancesco CA, MacKinnon DP, et al. Body Mass Index is a Predictor of Fire Fighter Injury and Worker Compensation Claims. J Occup Environ Med. 2012;54(5):579-82.

48. Hegg-Deloye S, Brassard P, Prairie J, Larouche D, Jauvin N, Poirer P, et al. Prevalence of risk factors for cardiovascular diseases in paramedics. Int Arch Occup Environ Health. 2015.

49. Merrill S. Task Performance and Health Improvement Recommendations for Emergency Medical Service Practitioners. United States: American Council on Exercise; 2013.

50. Fitness Passport. Fitness Passport 2018 [cited 2018 September 16]. Available from: https://www.fitnesspassport.com.au/.

51. McAdams MA, Van Dam R, Hu FB. Comparison of self-reported and measured BMI as correlates of disease markers in US adults. Obesity. 2007;15(1):188-196 